\title{
Upregulated osteoprotegerin expression promotes lung cancer cell invasion by increasing miR-20a expression
}

\author{
$\mathrm{KE} \mathrm{WAN}^{1,2^{*}}, \mathrm{ZIWEI} \mathrm{TU}^{3^{*}}, \mathrm{ZHENTIAN} \mathrm{LIU}^{2^{*}}, \mathrm{YUN} \mathrm{CAI}^{2^{*}}, \mathrm{YINGLAN} \mathrm{CHEN}^{2}$ and CHUNHUA LING ${ }^{1}$ \\ ${ }^{1}$ Department of Respiratory Diseases, The First Affiliated Hospital of Soochow University, Suzhou, Jiangsu 215000; \\ Departments of ${ }^{2}$ Thoracic Oncology and ${ }^{3}$ Radiation Oncology, Jiangxi Cancer Hospital, Nanchang, Jiangxi 330029, P.R. China
}

Received June 20, 2019; Accepted April 6, 2021

DOI: $10.3892 / \mathrm{etm} .2021 .10278$

\begin{abstract}
Osteoprotegerin (OPG) is a member of the tumor necrosis factor receptor superfamily and a major regulatory factor in osteoclast development. OPG has been previously associated with the malignant behavior of various types of cancer, particularly that of cancer metastasis. However, information on the link between the expression profile of OPG and lung cancer metastasis remained elusive. In the present study, the expression levels of OPG in the serum samples of patients with non-small cell lung cancer (NSCLC) was measured using ELISA. The expression of miRNAs was assessed using reverse transcription-quantitative PCR. A549 or H3122 cell invasion was assessed using Transwell invasion assays. The effect of OPG on the invasiveness of lung cancer cells was evaluated using an experimental mouse lung metastasis model. OPG expression was found to be upregulated in the serum of patients with NSCLC compared with that in healthy individuals. The serum levels of OPG in patients with distant metastasis were observably higher compared with those in patients without metastasis. Functionally, overexpression of OPG in NSCLC cells markedly promoted cell invasion. Mechanistically, increased expression of OPG resulted in upregulation of microRNA (miR)-20a in NSCLC cells. Furthermore, miR-20a promoted NSCLC cell invasion, whilst miR-20a inhibition partially abrogated the effect of OPG on NSCLC cell invasion. Taken together, the present results demonstrated that the OPG/miR-20a axis serve an important
\end{abstract}

Correspondence to: Dr Chunhua Ling, Department of Respiratory Diseases, The First Affiliated Hospital of Soochow University, 188 Shizi Street, Suzhou, Jiangsu 215000, P.R. China

E-mail: linchunhua88@hotmail.com

Dr Yinglan Chen, Department of Thoracic Oncology, Jiangxi Cancer Hospital, 519 East Beijing Road, Nanchang, Jiangxi 330029, P.R. China

E-mail: doc.cyl@163.com

${ }^{*}$ Contributed equally

Key words: osteoprotegerin, microRNA-20a, lung cancer, cell invasion role in lung cancer metastasis, which potentially provide an additional novel target for lung cancer treatment.

\section{Introduction}

Lung cancer is one of the most common causes of cancerassociated mortality worldwide, which affects $\sim 1.6$ million individuals every year (1). Non-small cell lung cancer (NSCLC) is the major subgroup of lung cancer that results in a large number of cancer-associated mortalities worldwide, which places substantial burden on patients, their families and society $(1,2)$. Despite improvements in multiple therapeutic approaches for NSCLC made over recent decades, including surgery, chemotherapy and radiotherapy, the survival rate of NSCLC remains low due to a high rate of distant metastasis and recurrence $(3,4)$. Since the underlying mechanism of tumorigenesis and distant metastasis remain poorly understood, progress in the development of targeted therapies to improve the NSCLC survival rate has been limited.

Osteoprotegerin (OPG) is a member of the tumor necrosis factor receptor superfamily that suppresses osteoclastogenesis by interrupting cell-to-cell interactions (5). OPG is primarily expressed as a circulating glycoprotein that is 401 amino acids long that was initially been identified as a bone-remodeling agent, which prevents osteolysis by inhibiting osteoclast differentiation and bone resorption $(2,6)$. However, a role of OPG in regulating tumor metastasis has been previously revealed (7). Holen and Shipman reported that OPG can bind to tumor necrosis factor-related apoptosis-inducing ligand (TRAIL) to block the activation of death receptors 4 and 5 (8). Therefore, OPG potentially serves an anti-apoptotic role in OPG-expressing cells by harnessing the mechanism of TRAIL induction $(8,9)$. Supporting this notion, previous studies demonstrated that OPG may be released into the serum of the patients with colorectal or myeloma to exert an anti-apoptotic effect on colorectal or myeloma cancer cells $(9,10)$. Weichhaus et al (11) also reported that suppression of OPG has an important suppressive role in breast cancer cell metastasis. Mechanistically, downregulation of OPG in breast cancer cells resulted in reducing metastasis by inhibiting the expression of proteases cathepsin D and matrix metalloproteinase 2 (11). Yu et al (2) indicated that OPG levels are observably upregulated in human lung cancer tissues compared with those in normal tissues. In addition, overexpression of OPG in lung 
cancer cells has been reported to contribute to cell invasion in vitro (2). In particular, an underlying regulatory interaction between OPG and microRNAs (miRNAs/miRs) in tumor progression has been previously revealed (12).

miRNAs are a class of small non-coding RNAs that regulate gene expression by targeting mRNA (13). miRNAs may serve as effective regulators of cell proliferation, apoptosis and carcinogenesis (14-16). Previous studies have demonstrated that compared with those in healthy individuals, expression of miRNAs are frequently dysregulated in patients with lung cancer, such that miRNAs may serve as biomarkers with predictive diagnostic and prognostic significance (17). Kuo et al (18) reported that miR-33a is an effective inhibitor of bone metastasis in lung cancer by repressing the expression of parathyroid hormone-related protein. In another study, Jia et al (12) suggested that estrogen regulates the expression of OPG after transcription by inhibiting the expression of miR-145 in human osteosarcoma cells.

Based on these previous observations aforementioned, the present study aimed to assess OPG expression in lung cancer tissues with or without distant metastasis and normal tissues. In addition, the present study also investigated the potential interaction between OPG and miRNAs in the regulation of lung cancer cell invasion.

\section{Materials and methods}

Patients and specimens. The protocols of the present study were approved by the Ethics Committee of Jiangxi Cancer Hospital (Nanchang, China). All volunteers had provided written informed consent prior to sample collection. Serum samples from healthy volunteers (sex, 24 males and 16 females; age, 54.45 \pm 7.27 ; age range, $42-73$ years) and patients with

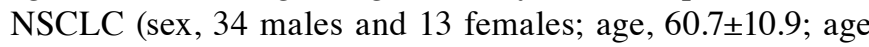
range, 42-83 years) was obtained at Jiangxi Cancer Hospital (Nanchang, China) from Jan 2017 to May 2019. The clinicopathological data of the patients with NSCLC are provided in Table I. Bone metastasis of NSCLC were diagnosed using computed tomography. The inclusion criteria for patients with NSCLC were as follows: i) Aged $<85$ years; and ii) imaging and pathological diagnosis of NSCLC stages I-IV according to TNM staging system (19). No patients received chemo- or radiotherapy when they were recruited. Exclusion criteria: i) Patients with type I or II diabetes or cardiovascular disease; ii) body mass index $>30$; and iii) patients with respiratory failure $\left(\mathrm{PaO}_{2}<60 \mathrm{mmHg}(20)\right.$, breathing room air at rest). The inclusion criteria for healthy volunteers were: i) Aged $<85$ years; and ii) non-tumor population. Exclusion criteria were: i) Patients with type I or II diabetes or cardiovascular disease; ii) body mass index $>30$; and iii) with respiratory failure $\left(\mathrm{PaO}_{2}<60 \mathrm{mmHg}\right.$, breathing room air at rest). All samples were collected, followed by ELISA and reverse transcription-quantitative PCR (RT-qPCR) analysis.

Cell lines. The human NSCLC cell lines A549 and H3122 were obtained from the American Type Culture Collection, and grown in DMEM (Gibco; Thermo Fisher Scientific, Inc.) supplemented with 10\% FBS (Gibco; Thermo Fisher Scientific, Inc.), $1 \%$ streptomycin and penicillin (Gibco; Thermo Fisher Scientific, Inc.) in a cell incubator at $37^{\circ} \mathrm{C}$ with $5 \% \mathrm{CO}_{2}$.
OPG overexpression. OPG was overexpressed using pcDNA3.1 plasmid vector (Thermo Fisher Scientific, Inc.). In brief, total RNA were extracted from A549 cells using TRIzol ${ }^{\circledR}$ kit (Thermo Fisher Scientific, Inc.) and cDNA was synthesized by reverse transcription PCR using iScripe ${ }^{\mathrm{TM}} \mathrm{cDNA}$ Synthesis kit (Bio-Rad Laboratories, Inc.) according to the manufacturer's protocols. The full-length coding sequence of OPG (GenBank no. U94332.1) was amplified from the cDNA using PCR and then inserted into the vector at the restriction sites $\mathrm{BamHI}$ and $X h a \mathrm{I}$ to form the recombinant plasmid pcDNA3-OPG. The specific primer sequences used for amplifying OPG cDNA were: Forward, 5'-cgggatcccgATGAACAAGTTGCT GTGCTGC-3', reverse, 5'-gctctagagcTTATAAGCAGCTTA TTTTTACTGATTGG-3'. pcDNA3-OPG plasmids (5 $\mu \mathrm{g})$ were transfected into A594 cells using Lipofectamine ${ }^{\circledR}$ 3000 (Invitrogen; Thermo Fisher Scientific, Inc.) for $48 \mathrm{~h}$ to overexpress OPG. pcDNA3 was used as the negative control.

ELISA.OPG protein levels in serum samples from patients with NSCLC with or without metastasis and healthy individuals were assessed using an ELISA kit (cat. no. EHTNFRSF11B; Invitrogen; Thermo Fisher Scientific, Inc.) as per the manufacturer's protocol. The absorbance of samples was measured at $450 \mathrm{~nm}$ with a microplate reader (Thermo Fisher Scientific, Inc.).

$R T$-qPCR. A total of 13 NSCLC-associated miRNAs were assessed using RT-qPCR. TRIzol ${ }^{\circledast}$ kit (Thermo Fisher Scientific, Inc.) was applied to isolate total RNA from A549 cells. Moloney's murine leukemiavirus reverse transcriptase (cat. no. 2641A; Takara Biotechnology Co., Ltd.) was used to perform reverse-transcription reaction using Oligo(dT) primers (Vazyme Biotech Co., Ltd.) and dNTPs (cat. no. 4035; Takara Bio, Inc.). The temperature protocol for reverse transcription was $70^{\circ} \mathrm{C}$ for $5 \mathrm{~min}$, followed by ice bath for $2 \mathrm{~min}$ and then $42^{\circ} \mathrm{C}$ for $60 \mathrm{~min}$. The specific reverse transcription primers for miR-20a were synthesized as previously described (21). qPCR was performed using TB Green ${ }^{\circledR}$ Premix Ex Taq ${ }^{\mathrm{TM}}$ (cat. no. RR420L; Takara Bio, Inc.) on a real-time PCR system (CFX96 Touch system; Bio-Rad Laboratories, Inc.). The thermocycling protocol for qPCR was $95^{\circ} \mathrm{C}$ for $10 \mathrm{~min}$, followed by 35 cycles of $95^{\circ} \mathrm{C}$ for $15 \mathrm{sec}$ and $58^{\circ} \mathrm{C}$ for $20 \mathrm{sec}$. The expression of OPG mRNA and 13 miRNAs was normalized to those of $\beta$-actin and U6, respectively. The primer sequences involved were listed in Table II. The qPCR results were analyzed and calculated using the $2^{-\Delta \triangle \mathrm{Cq}}$ method (22).

miR-20a mimics and inhibitor. Human miR-20a mimics (5'-UAAAGUGCUUAUAGUGCAGGUAG-3') and miR-20a inhibitor (5'-2'-O-methyl-CUACCUGCACUAUAAGCA CUUUA-3') were synthesized by Invitrogen (Thermo Fisher Scientific, Inc.), and applied to overexpress or inhibit miR-20a expression in A549 cells using Lipofectamine ${ }^{\circledR} 3000$ (Invitrogen; Thermo Fisher Scientific, Inc.) following the manufacturer's protocol. The overexpression/inhibition was identified using RT-qPCR analysis after transfection (80 ng miR-20a mimics or inhibitor) for $48 \mathrm{~h}$ (23). miRNA mimic Control (5'-UUCUCCGAACGUGUCACGUUU-3'; Invitrogen; Thermo Fisher Scientific, Inc.) and miRNA inhibitor control (5'-2'-O-methyl-AAACGUGACACGUUC 
Table I. Clinical characteristics of patients with primary non-small cell lung cancer.

\begin{tabular}{|c|c|c|c|c|}
\hline \multirow[b]{2}{*}{ Patient characteristics } & \multirow[b]{2}{*}{$\mathrm{N}$} & \multicolumn{2}{|c|}{ Osteoprotegerin expression ${ }^{\mathrm{a}}$} & \multirow[b]{2}{*}{ P-value ${ }^{b}$} \\
\hline & & Low & High & \\
\hline Sex & & & & 0.306 \\
\hline Female & 13 & 6 & 7 & \\
\hline Male & 34 & 15 & 18 & \\
\hline \multicolumn{5}{|l|}{ Age (years) } \\
\hline$\leq 60$ & 24 & 10 & 14 & 0.412 \\
\hline$>60$ & 23 & 11 & 12 & \\
\hline \multicolumn{5}{|l|}{ Histological type } \\
\hline Lung adenocarcinoma & 35 & 20 & 15 & 0.165 \\
\hline Lung squamous cell carcinoma & 12 & 7 & 5 & \\
\hline \multicolumn{5}{|l|}{ History of smoking } \\
\hline Yes & 27 & 12 & 15 & 0.081 \\
\hline No & 20 & 9 & 11 & \\
\hline \multicolumn{5}{|l|}{ TNM stage } \\
\hline I & 2 & 0 & 2 & 0.227 \\
\hline II & 3 & 1 & 2 & \\
\hline IIIA/IIIB/IIIC & 6 & 3 & 3 & \\
\hline IV & 36 & 15 & 21 & \\
\hline Bone metastasis & & & & 0.008 \\
\hline Yes & 16 & 5 & 11 & \\
\hline No & 31 & 13 & 18 & \\
\hline
\end{tabular}

${ }^{a}$ The median level of osteoprotegerin was used as the cutoff. Patients are sorted into OPG high expression (osteoprotegerin expression levels are higher than the median) and osteoprotegerin low expression. ${ }^{b}$ Fisher's exact test.

GGAGAA-3'; Invitrogen; Thermo Fisher Scientific, Inc.) were used as control after transfection $(80 \mathrm{ng})$ for $48 \mathrm{~h}$.

Western blot analysis. Total protein was extracted from A549 cells using RIPA Buffer (Beijing Solarbio Science \& Technology Co., Ltd.) and protein concentration was quantified using a bicinchoninic acid protein assay kit (Beijing Solarbio Science \& Technology Co., Ltd.). In total, $\sim 80 \mu \mathrm{g}$ total protein was separated by $12 \%$ SDS-PAGE and transferred onto PVDF membranes (Thermo Fisher Scientific, Inc.) as previously described (24). To measure the protein expression levels of OPG, the membranes were incubated with anti-OPG (cat. no. ab11994; $1: 1,000)$ and anti- $\beta$-actin (cat. no. ab179467, 1:5,000 dilution) primary antibodies (both from Abcam) for $2 \mathrm{~h}$ at room temperature. HRP-conjugated goat anti-mouse IgG Fc (cat. no. ab205719; 1:20,000 dilution; Abcam) or goat anti-rabbit IgG Fc (cat. no. ab97200; 1:20,000 dilution; Abcam) was used to as the secondary antibody to incubate the membranes for $2 \mathrm{~h}$ at room temperature. An ECL chemiluminescence kit (EMD Millipore) was used to visualize the specific blots and autoradiograms were quantified by densitometry with Quantity One ${ }^{\circledR}$ software (version 4.6.9; Bio-Rad Laboratories. Inc.) after normalizing to $\beta$-actin.

Transwell invasion assay. Transwell chambers $(8-\mu \mathrm{m}$ pore size) coated with Matrigel were purchased from
BD Biosciences (cat. no. 354481) and applied to evaluate the cell invasion capacity (25). Briefly, after transfection with pcDNA-OPG in the presence or absence of miR-20a inhibitor for $48 \mathrm{~h}, 3.0 \times 10^{4} \mathrm{~A} 549$ cells suspended in serum-free DMEM medium were seeded onto the upper chambers. Complete DMEM medium with $10 \%$ FBS was added into the lower chambers. Cells that had invaded into the lower chamber $48 \mathrm{~h}$ later were fixed with $4 \%$ formaldehyde for $15 \mathrm{~min}$ and stained with crystal violet $(0.1 \%)$ for $10 \mathrm{~min}$ at room temperature. The number of invaded cells was counted from three visual fields using an Olympus light microscope (Olympus Corporation) under x200 magnification.

Experimental lung metastasis assay. In total, $24 \mathrm{BALB} / \mathrm{c}$ nude female mice (weight, 20.6 $\pm 2.04 \mathrm{~g}$; age, 4-6 weeks; randomly divided into three groups of eight mice) were obtained from Shanghai Model Organisms Center, Inc. Mice were maintained in sterile conditions (temperature, $22-25^{\circ} \mathrm{C}$, humidity, 45-65\%) under a 12-h light/dark cycle with free access to water and food. All experimental protocols were approved by the Animal Committee of Jiangxi Cancer Hospital (Nanchang, China). A549 cells transfected with pcDNA-OPG with or without miR-20a inhibitor for $48 \mathrm{~h}\left(5 \times 10^{6} / 200 \mu \mathrm{l}\right.$ PBS) were injected through the tail vein of the nude mice $(26,27)$. Lung tissues were collected 10 weeks later for analysis of lung metastasis by gross anatomy after euthanasia. Euthanasia 
Table II. Primer sequences used in the present study.

\begin{tabular}{|c|c|}
\hline Name & Sequences $\left(5^{\prime} \rightarrow 3^{\prime}\right)$ \\
\hline OPG & $\begin{array}{l}\text { F: 5'-TGGACATGCTAACCTCACCTTCG-3 } \\
\text { R: 5'-GCCATTTTTTATTCGCCACAAAC-3' }\end{array}$ \\
\hline$\beta$-actin & $\begin{array}{l}\text { F: 5'-GTTGCCCTGAGGCTCTTTTCC-3' } \\
\text { R: 5'-CCACCAGACAGCACTGTGTTG-3' }\end{array}$ \\
\hline U6 & $\begin{array}{l}\text { F: 5'-CTCGCTTCGGCAGCACA-3' } \\
\text { R: 5'-AACGCTTCACGAATTTGCGT-3' }\end{array}$ \\
\hline microRNA-20a & $\begin{array}{l}\text { F: 5'-CGGCTAAAGTGCTTATAGTGCA-3' } \\
\text { R: 5'-GTGCAGGGTCCGAGGT-3' }\end{array}$ \\
\hline microRNA-200 & $\begin{array}{l}\text { F: 5'-CGGCTAACACTGTCTGGTAACG-3' } \\
\text { R: 5'-GTGCAGGGTCCGAGGT-3' }\end{array}$ \\
\hline microRNA-34 & $\begin{array}{l}\text { F: 5'-GCCGCAATCAGCAAGTATACT-3' } \\
\text { R: 5'-GTGCAGGGTCCGAGGT-3' }\end{array}$ \\
\hline microRNA-31 & $\begin{array}{l}\text { F: 5'-CCGGAGGCAAGAUGCUGGC-3' } \\
\text { R: 5'-GTGCAGGGTCCGAGGT-3' }\end{array}$ \\
\hline microRNA-221 & $\begin{array}{l}\text { F: 5'-CGGCAGCTACATTGTCTGCTGG-3' } \\
\text { R: 5'-GTGCAGGGTCCGAGGT-3' }\end{array}$ \\
\hline microRNA-222 & $\begin{array}{l}\text { F: 5'-CCGGCTCAGTAGCCAGTGTAG-3' } \\
\text { R: 5'-GTGCAGGGTCCGAGGT-3' }\end{array}$ \\
\hline Let-7 & $\begin{array}{l}\text { F: 5'-GCCTGAGGTAGTAAGTTGTA-3' } \\
\text { R: 5'-GTGCAGGGTCCGAGGT-3' }\end{array}$ \\
\hline microRNA-126 & $\begin{array}{l}\text { F: 5'-CGGCTCGTACCGTGAGTAAT-3' } \\
\text { R: 5'-GTGCAGGGTCCGAGGT-3' }\end{array}$ \\
\hline microRNA-125 & $\begin{array}{l}\text { F: 5'-CGGCCCTGAGACCCTTTAACC-3' } \\
\text { R: 5'-GTGCAGGGTCCGAGGT-3' }\end{array}$ \\
\hline microRNA-145 & $\begin{array}{l}\text { F: 5'-GGCGTCCAGTTTTCCCAGGAAT-3' } \\
\text { R: 5'-GTGCAGGGTCCGAGGT-3' }\end{array}$ \\
\hline microRNA-21 & $\begin{array}{l}\text { F: 5'-CCGGTAGCTTATCAGACTGAT-3' } \\
\text { R: 5'-GTGCAGGGTCCGAGGT-3' }\end{array}$ \\
\hline microRNA-146a & $\begin{array}{l}\text { F: 5'-CGGCCTCTGAAATTCAGTTC-3' } \\
\text { R: 5'-GTGCAGGGTCCGAGGT-3' }\end{array}$ \\
\hline microRNA-141 & $\begin{array}{l}\text { F: 5'-GCCTAACACTGTCTGGTAAAG-3' } \\
\text { R: 5'-GTGCAGGGTCCGAGGT-3' }\end{array}$ \\
\hline
\end{tabular}

Let-7, lethal-7.

was performed by $\mathrm{CO}_{2}$ inhalation at $20 \% \mathrm{~V} / \mathrm{min}$ for $5 \mathrm{~min}$ followed by cervical dislocation. Humane endpoints included dehydration, weight loss $>15 \%$, hunched appearance and severe lameness. None of mice exhibited these humane endpoint criteria.

$H \& E$ (hematoxylin and eosin) staining. Murine lung tissues were fixed with $4 \%$ paraformaldehyde for $30 \mathrm{~min}$ at room temperature, dehydrated with an ascending gradient of ethanol and embedded in paraffin. The tissues were then cut into $5-\mu \mathrm{m}$ sections, deparaffinized with xylene for $20 \mathrm{~min}$ and stained with hematoxylin for $1 \mathrm{~h}$ and then with eosin for $1 \mathrm{~h}$ (Beyotime Institute of Biotechnology) at room temperature. The sections were photographed using a light microscope (BX41; Olympus Corporation) and observed under x200 magnification.
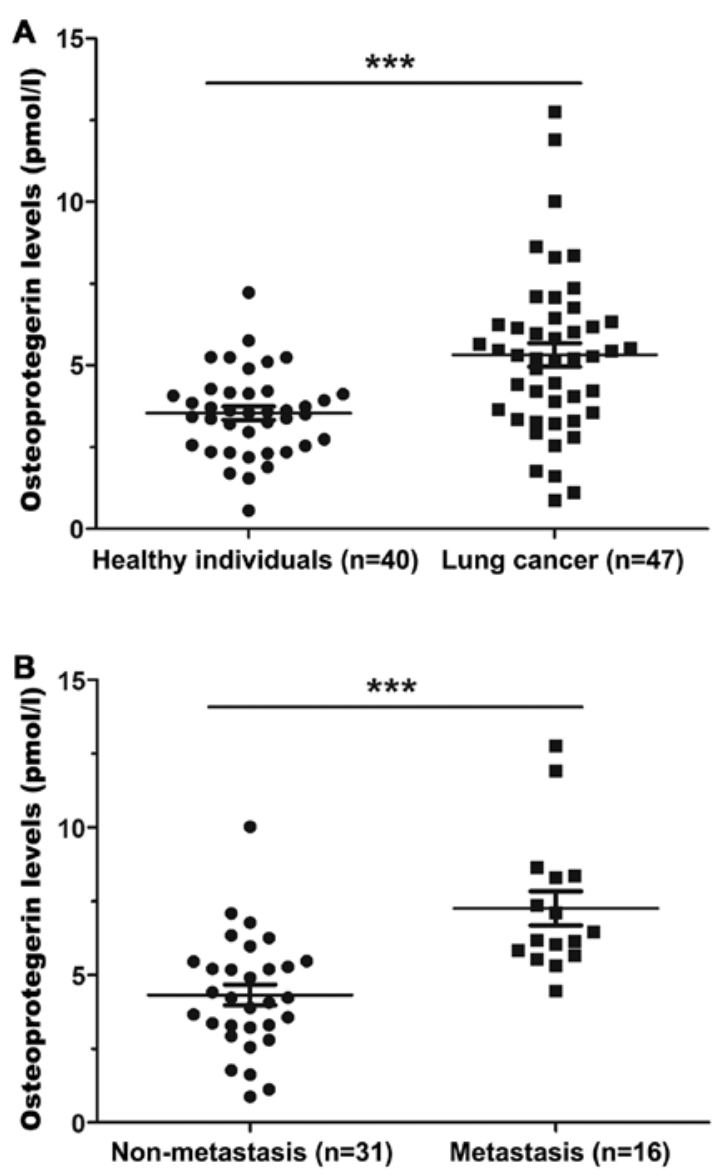

Figure 1. Measurement of OPG levels in the serum of patients with NSCLC. (A) ELISA of OPG levels in the serum of 47 patients with NSCLC and 40 healthy individuals. (B) ELISA of OPG levels in the serum of 16 patients with NSCLC with distant metastasis and 31 patients with NSCLC without distant metastasis. ${ }^{* * *} \mathrm{P}<0.001$. NSCLC, non-small cell lung cancer. OPG, osteoprotegerin; NSCLC, non-small cell lung cancer.

Statistical analysis. The SPSS 16.0 statistical analysis software (SPSS, Inc.) was used for data analysis. Values are expressed as the mean \pm standard deviation from $\geq$ three separate experiments. Unpaired Student's t-test (Figs. 1-3) and one-way analysis of variance followed by Scheffé test (Figs. 4 and 5) were applied to analyze differences between two groups and those among $\geq$ three groups, respectively. Data in Table I was analyzed using Fisher's exact test. $\mathrm{P}<0.05$ was considered to indicate a statistically significant difference.

\section{Results}

OPG expression is significantly upregulated in patients with NSCLC. Previous studies have demonstrated that upregulated OPG expression in lung cancer tissues is associated with cancer metastasis and worse survival $(2,28)$. In the present study, OPG levels were detected in the serum of patients with NSCLC. ELISA results suggested that OPG levels were significantly elevated in the serum of patients compared with those in healthy individuals (Fig. 1A). Furthermore, OPG levels were significantly increased in the serum samples of patients with bone metastasis compared with those in the serum of patients in non-metastatic group (Fig. 1B). In addition, no association was found between OPG expression and 

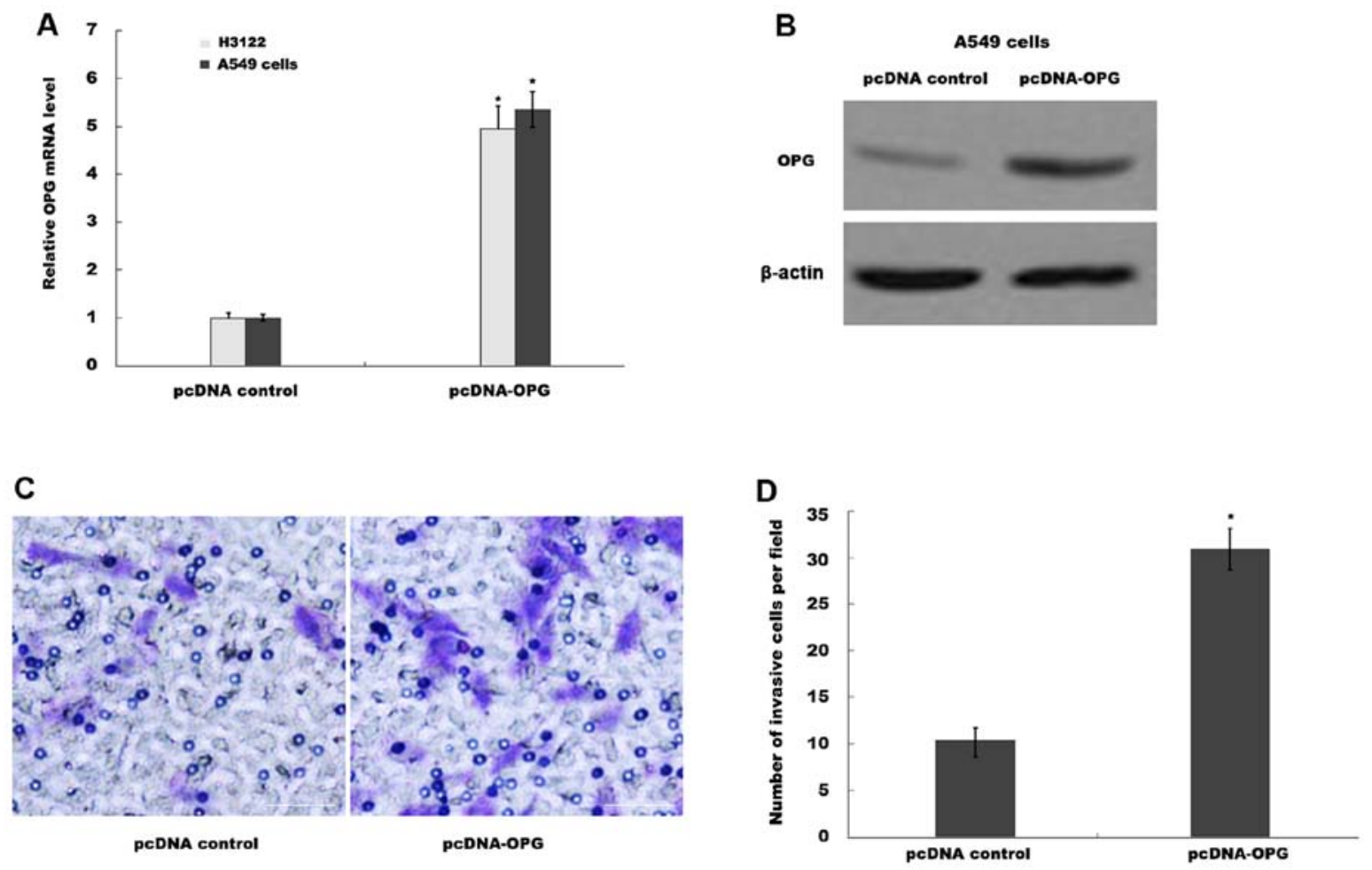

Figure 2. OPG promotes NSCLC cell invasion. (A) Reverse transcription-quantitative PCR analysis of OPG expression after pcDNA-OPG transfection in H3122 and A549 cells. "P $<0.05$ vs. pcDNA control. (B) Western blot analysis of OPG expression after pcDNA-OPG transfection in A549 cells. $\beta$-actin was used to internal control. (C) Cell invasion assay of A549 cells after OPG overexpression for $48 \mathrm{~h}$, scale bars, $100 \mu \mathrm{m}$. (D) which was quantified. ${ }^{*} \mathrm{P}<0.05 \mathrm{vs}$. pcDNA control. NSCLC, non-small cell lung cancer; OPG, osteoprotegerin; NSCLC, non-small cell lung cancer.
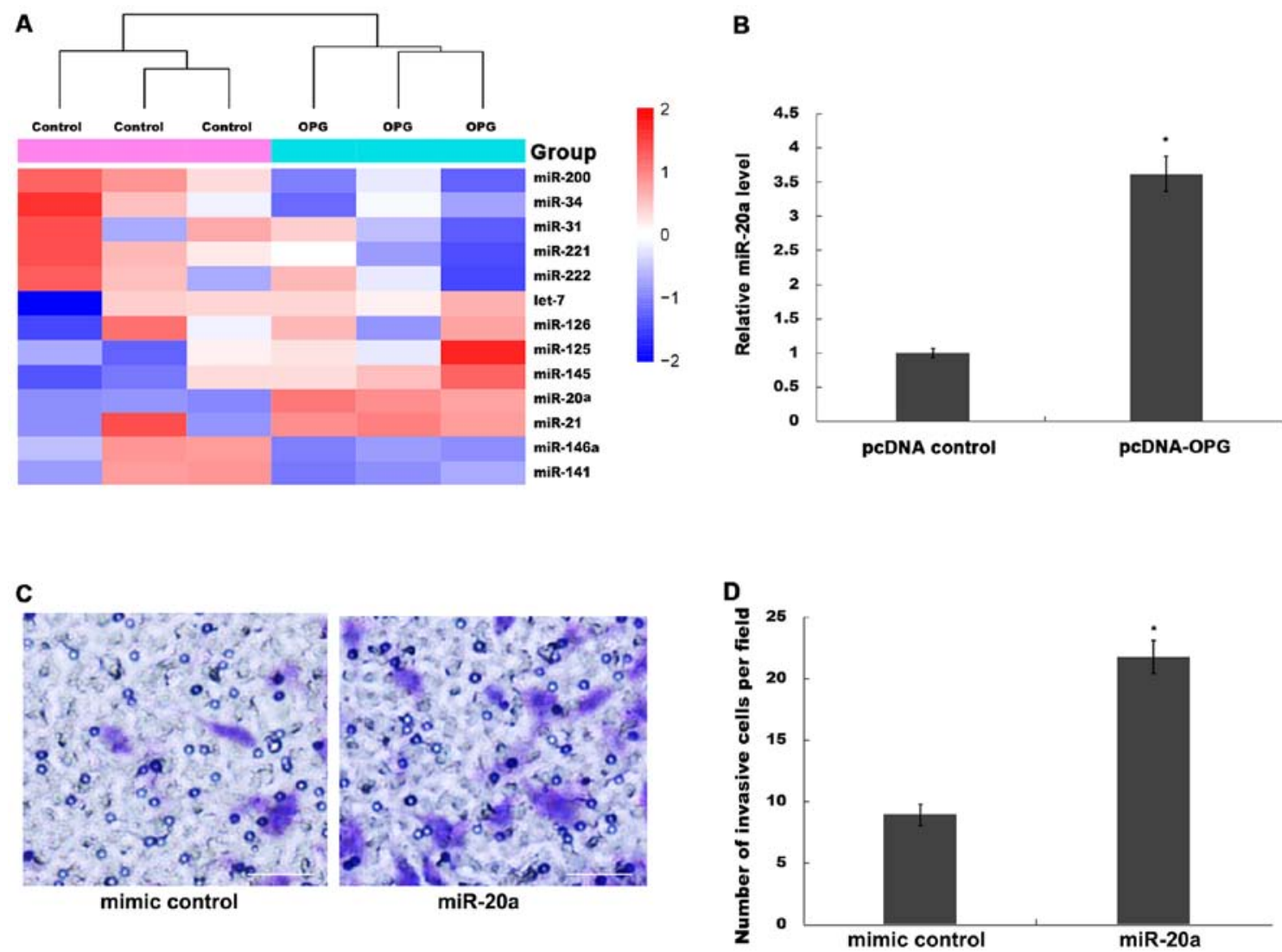

Figure 3. Overexpression of OPG results in increased miR-20a expression. (A) Reverse transcription-quantitative PCR analysis of 13 miRNAs in A549 cells after OPG overexpression. (B) Reverse transcription-quantitative PCR analysis of miR-20a expression after pcDNA-OPG transfection in A549 cells. ${ }^{*} \mathrm{P}<0.05$ vs. pcDNA control. (C) Cell invasion assay of A549 cells after miR-20a mimic transfection for $48 \mathrm{~h}$. Scale bars, $100 \mu \mathrm{m}$. (D) which was quantified. "P<0.05 vs. mimic control. OPG, osteoprotegerin; miR, microRNA; let-7, lethal-7; Cont, control. 


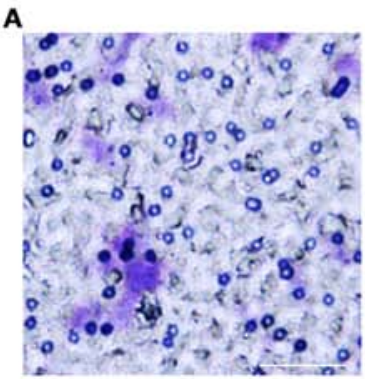

pCDNA control

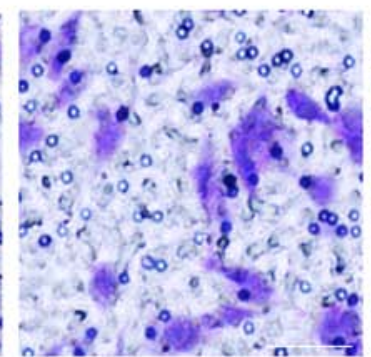

PCDNA-OPG

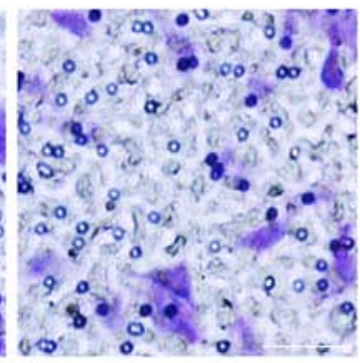

PCDNA-OPG+miR-20a inhibitor

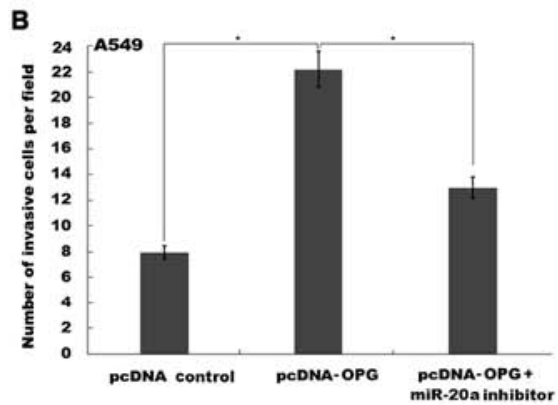

c

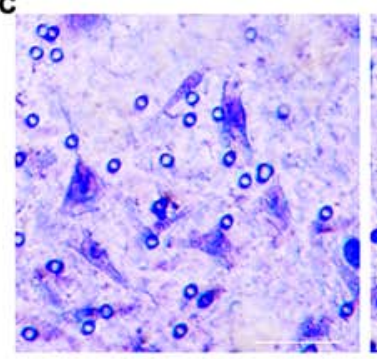

peDNA control
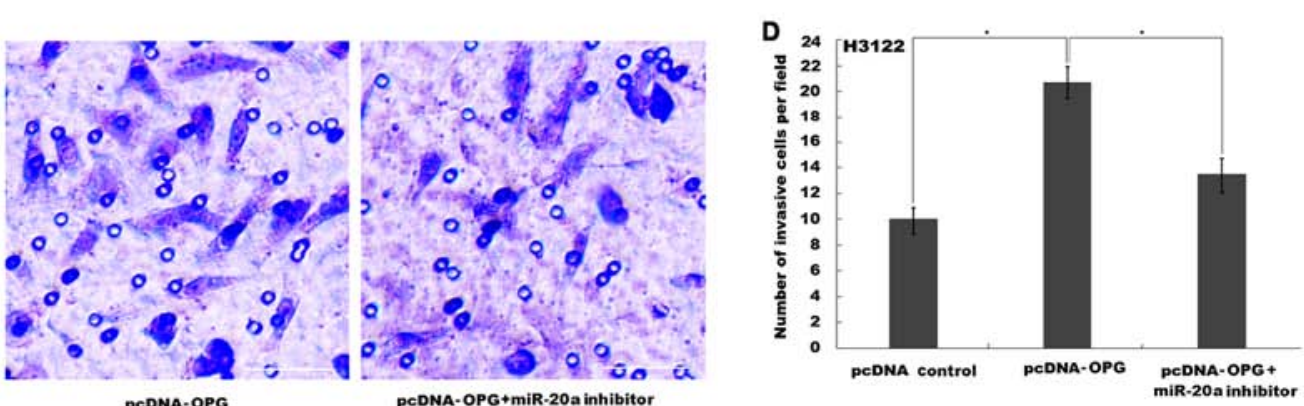

Figure 4. OPG increases the invasive ability of non-small cell lung cancer cells by upregulating miR-20a in vitro. (A) Cell invasion assay of A549 cells following OPG overexpression with or without miRNA-20a inhibition for $48 \mathrm{~h}$. Scale bars, $100 \mu \mathrm{m}$. (B) which was quantified. (C) Cell invasion assay of H3122 cells following OPG overexpression with or without miRNA-20a inhibition for $48 \mathrm{~h}$. Scale bars, $100 \mu \mathrm{m}$. (D) which was quantified. *P<0.05. OPG, osteoprotegerin, miR, microRNA.
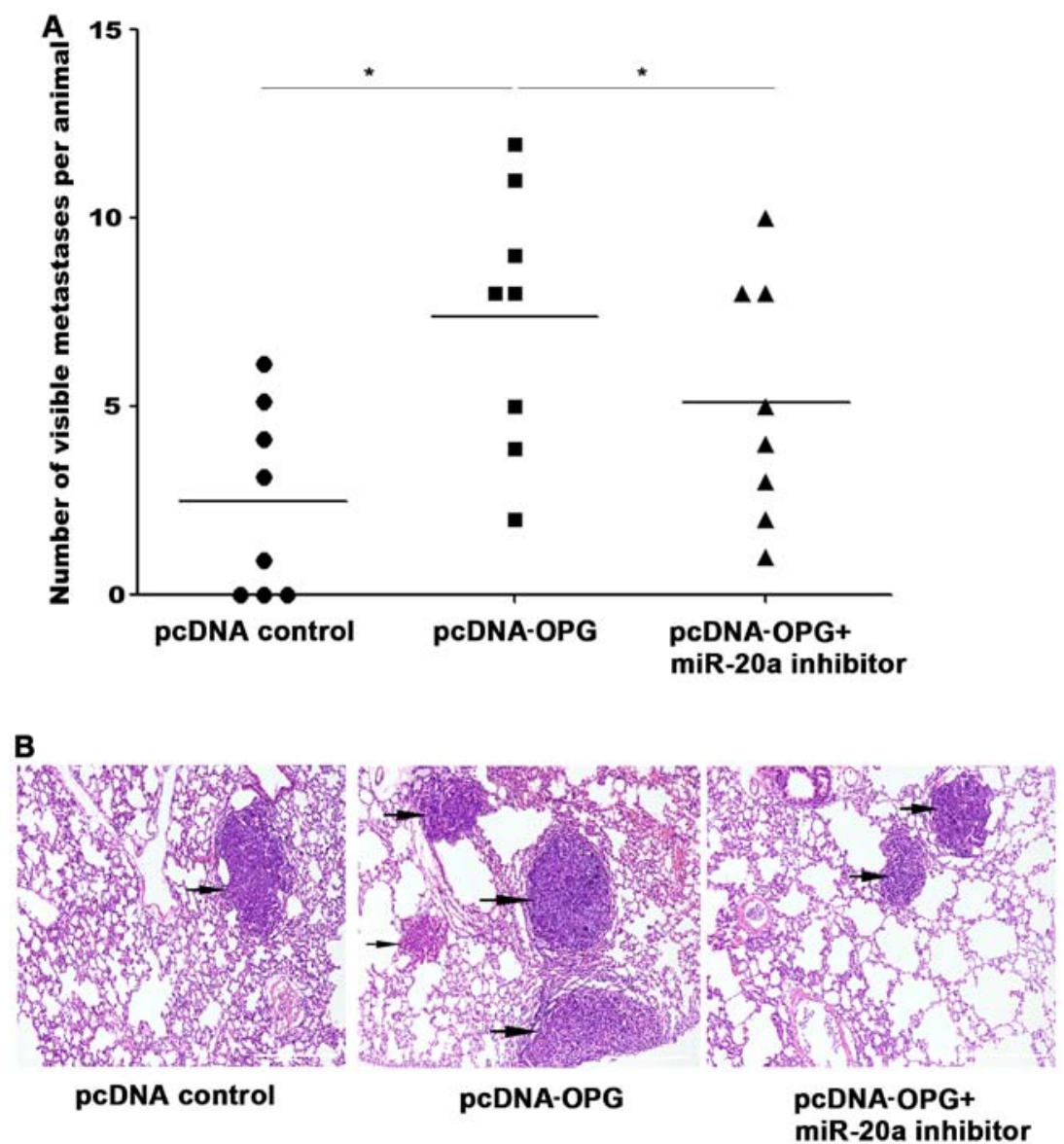

Figure 5. OPG promotes non-small cell lung cancer metastasis by upregulating miR-20a expression in vivo. (A) Visible lung metastasis was assessed after OPG overexpression in the presence or absence of miRNA-20a inhibitor 10 weeks after tail vein injection $(\mathrm{n}=8) .{ }^{*} \mathrm{P}<0.05$. (B) Hematoxylin and eosin staining analysis of the effects of OPG overexpression and/or miR-20a inhibitor co-transfection on the formation of lung metastasis. The arrows represent metastatic colonies formed by A549 cells. Scale bars, $100 \mu \mathrm{m}$. NSCLC, non-small cell lung cancer; OPG, osteoprotegerin; miR, microRNA. 
the clinicopathological features of patients with NSCLC, specifically sex, age, history of smoking, histological type and TNM stage (Table I).

OPG overexpression promotes NSCLC cell invasion. The biological effects of OPG on NSCLC cell lines were then explored further. A549 and $\mathrm{H} 3122$ cells were first transfected with the appropriate pcDNA control or pcDNA-OPG plasmids, before RT-qPCR and western blot analyses were performed to verify overexpression in the cell lines. The mRNA levels of OPG were significantly increased in H3122 and A549 cells transfected with pcDNA-OPG compared with those transfected with pcDNA control (Fig. 2A). This observation was confirmed further by western blot analysis in A549 cells (Fig. 2B). Functionally, OPG overexpression significantly increased the invasive ability of A549 cells compared with that in the pcDNA control group (Fig. 2C and D).

Overexpression of OPG results in increased miR-20a expression. Next, the potential mechanism of the function of OPG in NSCLC cell invasion were explored. Given the important role of miRNAs in NSCLC progression (29) and the previously reported association between OPG and miRNAs (30), it was investigated whether OPG promoted NSCLC cell invasion in a miRNA-dependent manner. A total of 13 NSCLC-associated miRNAs $(29,31-33)$ were selected as candidate targets that can be regulated by OPG (Table SI). As presented in Fig. 3A, the levels of miR-20a and miR-21 were found to be significantly upregulated (fold change $>2.0$ and $\mathrm{P}<0.05$ ) whereas the levels of miR-200 and miR-34 were significantly downregulated (fold change $<0.5$ and $\mathrm{P}<0.05$ ) after OPG overexpression in A549 cells compared with pcDNA control. The present study focused on miR-20a and its possible biological function in A549 cells was investigated because there was no effect of miR-21 in on OPG-induced cell invasion (data not shown). Significantly increased expression of miR-20a in A549 cells after OPG overexpression was confirmed compared with those transfected with the pcDNA control (Fig. 3B). Functionally, miR-20a overexpression in A549 cells significantly promoted cell invasion compared with transfected with the mimic control (Figs. 3C, D and S1).

OPG promotes NSCLC metastasis by upregulating miR-20a in vitro and in vivo. The results aforementioned suggested that OPG possessed the potential to activate miR-20a expression in NSCLC cells and promote cell invasion, whilst that miR-20a overexpression alone also contributed to NSCLC cell invasion. It was therefore speculated that OPG may promote NSCLC cell invasion by regulating miR-20a expression. OPG overexpression significantly promoted A549 cell invasion, whereas miR-20a inhibition by its specific inhibitor significantly reversed this effect (Figs. 4A, B and S1). Similarly, OPG overexpression also significantly promoted $\mathrm{H} 3122$ cells invasion, which was significantly reversed by miR-20a inhibition (Figs. 4C, D and S1).

Results from the in vivo experiments appeared to be consistent with the in vitro data. The number of lung metastases in mice in the OPG overexpression group was increased compared with those in the pcDNA control group. Conversely, co-transfection with the miR-20a inhibitor resulted in the reversal of this increase (Fig. 5A). Histological analysis verified that this OPG-induced potentiation of lung metastasis was partially repressed by inhibiting miR-20a (Fig. 5B).

\section{Discussion}

OPG is normally produced by osteoblasts and stromal cells and functions as a decoy receptor for RANKL to suppress osteoclast differentiation and activation (28). This is achieved by blocking the interaction between RANKL and its receptor RANK (34). OPG was initially defined as a protein that regulates bone resorption $(9,35)$. However, over the past decade the role of OPG in the regulation of carcinogenesis and tumor progression has been gradually revealed. Yu et al (2) previously analyzed OPG expression in lung cancer using The Cancer Genome Atlas (TCGA) project lung cancer database, which revealed that OPG expression is higher in lung cancer tissues compared. Data from TCGA seem to exhibit similar trends compared with those that were previously reported in a wide range of solid tumors types, including prostate, breast, pancreatic and colorectal $(2,36,37)$. Yu et al (2) also investigated the biological function of OPG in H3122 lung cancer cells, which found that OPG overexpression enhanced the malignant phenotypes of lung cancer cells in vitro.

Metastasis is a multifactorial and multistep dynamic process, which are the primary causes of poor prognosis and mortality associated with cancer (38). Patients with advanced lung cancer are more prone to bone metastasis, which seriously affects their daily activities and reduces their quality of life (39). Several bone formation markers, including OPG, RANKL and osteocalcin exhibit lower levels in tumor tissues without bone metastasis compared with those in tumor tissues with lung cancer and bone metastasis (39), indicating that these molecules may serve a potential role in lung cancer metastasis.

In the present study, OPG expression was first assessed in the serum of patients with NSCLC, revealing that OPG was increased in patients with NSCLC compared with those in healthy individuals. In addition, OPG levels were also significantly increased in the serum of patients with bone metastases compared with that in patients with non-metastatic NSCLC. The downstream biological effects of OPG on NSCLC cells were then investigated. Overexpression of OPG in A549 cells promoted cell invasion compared with that in the pcDNA control group. The relationship of OPG with miRNA expression was next investigated, since aberrant OPG expression has been reported to result in the dysregulation of certain miRNA profiles (40). Although the association between OPG and miRNAs has been described in previous studies $(12,41)$, the novelty of the present study lied in the verification that upregulated OPG promotes lung cancer cell invasion by increasing miR-20a expression. After overexpression of OPG in A549 cells, the differentially expressed miRNAs associated with NSCLC progression were examined using qPCR analysis, where the results suggested that miR-20a levels were observably upregulated following the overexpression of OPG. Overexpression of miR-20a in A549 and H1322 cells markedly facilitated cell invasion compared with that in the mimic control group. Additionally, both in vitro and in vivo, miR-20a inhibition in A549 and H1322 cells suppressed OPG-induced cell invasion and A549 metastasis. It is noteworthy that, 
although the expression of miR-21, miR-200 and miR-34 was also found to be dysregulated following the overexpression of OPG, these miRNAs did not affect the function of OPG in facilitating cell invasion (data not shown). The present results suggest that the OPG/miR-20a axis is a functional mechanistic node in the regulation of lung cancer metastasis, which provides a novel target for the development of novel targeted lung cancer therapies.

\section{Acknowledgements}

Not applicable.

\section{Funding}

The present study was supported by the project of the Jiangxi provincial Health commission (grant no. 20175400); the National Natural Science Foundation of China (grant no. 81660453); the Youth Foundation of Jiangxi Science and Technology Department (grant no. 20161BAB215255) and the Six Talent Peaks Project of Jiangsu Province (grant no. WS-053).

\section{Availability of data and materials}

The datasets used and/or analyzed during the current study are available from the corresponding author on reasonable request.

\section{Authors' contributions}

KW and ZWT participated in the design of the main research ideas and manuscript correction. ZTL and YC mainly performed the experiments. YLC and CHL made statistical analysis of the final data and agreed to publish the paper. All the authors read and approved the final manuscript. CHL and $\mathrm{KW}$ confirm the authenticity of raw data in the study.

\section{Ethics approval and consent to participate}

The protocols of the present study were approved by the Ethics Committee of Jiangxi Cancer Hospital (Nanchang, China). All patients and volunteers provided written informed consent.

\section{Patient consent for publication}

Not applicable.

\section{Competing interests}

The authors declare that they have no competing interests.

\section{References}

1. Molina JR, Yang P, Cassivi SD, Schild SE and Adjei AA Non-small cell lung cancer: Epidemiology, risk factors, treatment, and survivorship. Mayo Clin Proc 83: 584-594, 2008.

2. Yu Z, Sanders AJ, Owen S, Cheng S, Yang X and Jiang WG: Expression of osteoprotegrin is enhanced in lung cancer tissues and promotes aggressive cellular traits in $\mathrm{H} 3122$ lung cancer cells. Anticancer Res 37: 4277-4283, 2017.

3. Yano T, Okamoto T, Fukuyama S and Maehara Y: Therapeutic strategy for postoperative recurrence in patients with non-small cell lung cancer. World J Clin Oncol 5: 1048-1054, 2014.
4. Coello MC, Luketich JD, Litle VR and Godfrey TE: Prognostic significance of micrometastasis in non-small-cell lung cancer. Clin Lung Cancer 5: 214-225, 2004.

5. Yasuda H, Shima N, Nakagawa N, Yamaguchi K, Kinosaki M, Mochizuki S, Tomoyasu A, Yano K, Goto M, Murakami A, et al: Osteoclast differentiation factor is a ligand for osteoprotegerin/osteoclastogenesis-inhibitory factor and is identical to TRANCE/RANKL. Proc Natl Acad Sci USA 95: 3597-3602, 1998.

6. Weichhaus M, Chung ST and Connelly L: Osteoprotegerin in breast cancer: Beyond bone remodeling. Mol Cancer 14: 117, 2015.

7. Renema N, Navet B, Heymann MF, Lezot F and Heymann D: RANK-RANKL signalling in cancer. Biosci Rep 36: e00366, 2016.

8. Holen I and Shipman CM: Role of osteoprotegerin (OPG) in cancer. Clin Sci (Lond) 110: 279-291, 2006.

9. Tsukamoto S, Ishikawa T, Iida S, Ishiguro M, Mogushi K, Mizushima H, Uetake H, Tanaka H and Sugihara K: Clinical significance of osteoprotegerin expression in human colorectal cancer. Clin Cancer Res 17: 2444-2450, 2011.

10. Shipman CM and Croucher PI: Osteoprotegerin is a soluble decoy receptor for tumor necrosis factor-related apoptosisinducing ligand/Apo2 ligand and can function as a paracrine survival factor for human myeloma cells. Cancer Res 63: 912-916, 2003.

11. Weichhaus M, Segaran P, Renaud A, Geerts D and Connelly L: Osteoprotegerin expression in triple-negative breast cancer cells promotes metastasis. Cancer Med 3: 1112-1125, 2014.

12. Jia J, Zhou H, Zeng $X$ and Feng S: Estrogen stimulates osteoprotegerin expression via the suppression of miR-145 expression in MG-63 cells. Mol Med Rep 15: 1539-1546, 2017.

13. Zhao Q, Li P, Ma J and Yu X: MicroRNAs in lung cancer and lung cancer bone metastases: Biomarkers for early diagnosis and targets for treatment. Recent Pat Anticancer Drug Discov 10: 182-200, 2015.

14. Hwang HW and Mendell JT: MicroRNAs in cell proliferation, cell death, and tumorigenesis. Br J Cancer 94: 776-780, 2006.

15. Saito Y, Suzuki H, Tsugawa H, Nakagawa I, Matsuzaki J, Kanai $Y$ and Hibi T: Chromatin remodeling at Alu repeats by epigenetic treatment activates silenced microRNA-512-5p with downregulation of Mcl-1 in human gastric cancer cells. Oncogene 28: 2738-2744, 2009.

16. Bao B, Ali S, Kong D, Sarkar SH, Wang Z, Banerjee S, Aboukameel A, Padhye S, Philip PA and Sarkar FH: Anti-tumor activity of a novel compound-CDF is mediated by regulating miR-21, miR-200, and PTEN in pancreatic cancer. PLoS One 6: e17850, 2011.

17. Fanini F, Vannini I, Amadori D and Fabbri M: Clinical implications of microRNAs in lung cancer. Semin Oncol 38: 776-780, 2011.

18. Kuo PL, Liao SH, Hung JY, Huang MS and Hsu YL: MicroRNA-33a functions as a bone metastasis suppressor in lung cancer by targeting parathyroid hormone related protein. Biochim Biophys Acta 1830: 3756-3766, 2013.

19. Salgado RA, Snoeckx A, Spinhoven M, Op de Beeck B, Corthouts B and Parizel PM: Update in non small-cell lung cancer staging. JBR-BTR 96: 118-122, 2013.

20. Magnet FS, Majorski DS, Callegari J, Schwarz SB, Schmoor C, Windisch $\mathrm{W}$ and Storre $\mathrm{JH}$ : Capillary $\mathrm{PO}_{2}$ does not adequately reflect arterial $\mathrm{PO}_{2}$ in hypoxemic COPD patients. Int J Chron Obstruct Pulmon Dis 12: 2647-2653, 2017.

21. Chen C, Ridzon DA, Broomer AJ, Zhou Z, Lee DH, Nguyen JT, Barbisin M, Xu NL, Mahuvakar VR, Andersen MR, et al: Real-time quantification of microRNAs by stem-loop RT-PCR. Nucleic Acids Res 33: e179, 2005.

22. Livak KJ and Schmittgen TD: Analysis of relative gene expression data using real-time quantitative PCR and the 2(-Delta Delta C(T)) method. Methods 25: 402-408, 2001.

23. Cao Y, Zhao D, Li P, Wang L, Qiao B, Qin X, Li L and Wang Y: MicroRNA-181a-5p impedes IL-17-induced nonsmall cell lung cancer proliferation and migration through targeting VCAM-1. Cell Physiol Biochem 42: 346-356, 2017.

24. Kapinas K, Kessler CB, Ricks T, Gronowicz G and Delany AM: miR-29 modulates WNT signaling in human osteoblasts through a positive feedback loop. J Biol Chem 285: 25221-25231, 2010.

25. Connor KM, Hempel N, Nelson KK, Dabiri G, Gamarra A, Belarmino J, Van De Water L, Mian BM and Melendez JA: Manganese superoxide dismutase enhances the invasive and migratory activity of tumor cells. Cancer Res 67: 10260-10267, 2007. 
26. Zhuo W, Liu Y, Li S, Guo D, Sun Q, Jin J, Rao X, Li M, Sun M, Jiang M, et al: Long noncoding RNA GMAN, Up-regulated in gastric cancer tissues, is associated with metastasis in patients and promotes translation of ephrin A1 by competitively binding GMAN-AS. Gastroenterology 156: 676-691.e11, 2019

27. Wang W, Ma J, Jin F and Liao J: Hyperbranched polymer drug delivery treatment for lung metastasis of salivary adenoid cystic carcinoma in nude mice. Exp Ther Med 14: 3105-3111, 2017.

28. Naumnik W, Plonska I, Ossolinska M, Niklinski J and Naumnik B: Prognostic value of osteoprotegerin and SRANKL in bronchoalveolar lavage fluid of patients with advanced non-small cell lung cancer. Adv Exp Med Biol 1047: 1-6, 2018.

29. Weidle UH, Birzele F and Nopora A: MicroRNAs as potential targets for therapeutic intervention with metastasis of non-small cell lung cancer. Cancer Genomics Proteomics 16: 99-119, 2019.

30. Kanzaki H, Wada S, Yamaguchi Y, Katsumata Y, Itohiya K, Fukaya S, Miyamoto Y, Narimiya T, Noda K and Nakamura Y: Compression and tension variably alter Osteoprotegerin expression via miR-3198 in periodontal ligament cells. BMC Mol Cell Biol 20: 6, 2019.

31. Zhong S, Golpon H, Zardo P and Borlak J: miRNAs in lung cancer. A systematic review identifies predictive and prognostic miRNA candidates for precision medicine in lung cancer. Transl Rese 230: 164-196, 2021

32. Petrek H and Yu AM: MicroRNAs in non-small cell lung cancer: Gene regulation, impact on cancer cellular processes, and therapeutic potential. Pharmacol Res Perspect 7: e00528, 2019.

33. Xu X, Zhu S, Tao Z and Ye S: High circulating miR-18a, miR-20a, and miR-92a expression correlates with poor prognosis in patients with non-small cell lung cancer. Cancer Med 7: 21-31, 2018.

34. Sisay M, Mengistu G and Edessa D: The RANK/RANKL/OPG system in tumorigenesis and metastasis of cancer stem cell: Potential targets for anticancer therapy. Onco Targets Ther 10: 3801-3810, 2017.
35. Theoleyre S, Wittrant Y, Tat SK, Fortun Y, Redini F and Heymann D: The molecular triad OPG/RANK/RANKL: Involvement in the orchestration of pathophysiological bone remodeling. Cytokine Growth Factor Rev 15: 457-475, 2004.

36. Brown JM, Corey E, Lee ZD, True LD, Yun TJ, Tondravi M and Vessella RL: Osteoprotegerin and rank ligand expression in prostate cancer. Urology 57: 611-616, 2001.

37. Shi W, Qiu W, Wang W, Zhou X, Zhong X, Tian G and Deng A Osteoprotegerin is up-regulated in pancreatic cancers and correlates with cancer-associated new-onset diabetes. Biosci Trends 8: 322-326, 2014.

38. Wu S, Pan Y, Mao Y, Chen Y and He Y: Current progress and mechanisms of bone metastasis in lung cancer: A narrative review. Transl Lung Cancer Res 10: 439-451, 2021.

39. Mountzios G, Ramfidis V, Terpos E and Syrigos KN: Prognostic significance of bone markers in patients with lung cancer metastatic to the skeleton: A review of published data. Clin Lung Cancer 12: 341-349, 2011.

40. Pitari MR, Rossi M, Amodio N, Botta C, Morelli E, Federico C, Gullà A, Caracciolo D, Di Martino MT, Arbitrio M, et al: Inhibition of miR-21 restores RANKL/OPG ratio in multiple myeloma-derived bone marrow stromal cells and impairs the resorbing activity of mature osteoclasts. Oncotarget 6: 27343-27358, 2015.

41. Zhan FL, Liu XY and Wang XB: The Role of MicroRNA-143-5p in the differentiation of dental pulp stem cells into odontoblasts by targeting Runx 2 via the OPG/RANKL signaling pathway. J Cell Biochem 119: 536-546, 2018.

This work is licensed under a Creative Commons Attribution-NonCommercial-NoDerivatives 4.0 International (CC BY-NC-ND 4.0) License. 